\title{
Método Lêcom: a relevância de aspectos ergonômicos para a construção de procedimentos que visam mensurar o rendimento de leitura com crianças brasileiras
}

\author{
Daniel Alvares Lourenço; \\ Solange Galvão Coutinho \\ (1) Instituto Federal da Paraíba, Doutor em Design \\ e-mail: lourencodesign@gmail.com \\ (2) Universidade Federal de Pernambuco, Ph.D. em Typography \& Graphic \\ Communication \\ e-mail: solange.coutinho@pq.cnpq.br
}

\begin{abstract}
RESUMO
Este artigo objetiva apresentar as etapas metodológicas do Método Lêcom, um método voltado para mensurar o rendimento da leitura de crianças no segundo ano do ensino fundamental de escolas públicas brasileiras, a partir dos fundamentos da legibilidade e leiturabilidade, juntamente com aspectos da lectoescrita. No decorrer da aplicação do método, as crianças devem ler e copiar frases projetadas por um datashow, onde alguns princípios da ergonomia visual foram essenciais para construir as etapas do método e posteriormente aplica-las com as crianças.
\end{abstract}

\section{ABSTRACT}

The aim of this article is to present the methodological steps of the Lêcom method, which measures the performance of children's reading in the second year of primary education in Brazilian public schools, using legibility and readability as its basis, along with aspects of learning to read and write. During the application of this method, children should read and copy phrases projected through a datashow, where certain principles of visual ergonomics were essential for building the steps of the method and then afterwards applying them to children.

\section{INTRODUÇÃO}

Este artigo apresenta um recorte da etapa metodológica da tese de doutorado: Desenvolvimento de um método para avaliação do rendimento de leitura com crianças brasileiras envolvendo legibilidade, leiturabilidade e fundamentos da lectoescrita Método Lêcom (LOURENÇO, 2016).

Diversas são as lacunas quando o assunto é tipografia para leitores iniciantes, principalmente sobre as crianças do ensino fundamental da rede pública brasileira. Poucas pesquisas têm sido realizadas sobre o tema no país, e aquelas desenvolvidas, fundamentam-se em pesquisas europeias, mais especificamente nas inglesas.

Tornou-se premissa desenvolver uma pesquisa com crianças brasileiras, ao mesmo tempo em que se verificou a necessidade em desenvolver uma metodologia de análise da leitura, mais especificamente da legibilidade e leiturabilidade envolvendo 
crianças do segundo ano do ensino fundamental de escolas públicas brasileiras, visto que as mesmas se encontram em pleno processo de letramento.

Em busca de respostas, foi desenvolvido um desenho metodológico de forma a observar sistematicamente o ensino da leitura; da escrita realizada pelos professores; e, como são transmitidos tais conteúdos para as crianças do primeiro e segundo ano do ensino fundamental. O percurso do estudo envolveu observar e analisar empiricamente todos estes aspectos unindo os conhecimentos obtidos na fundamentação teórica e pesquisa exploratória da investigação.

Para tal, uma parte da pesquisa exploratória se deu por meio do contato com educadores do primeiro e segundo ano do ensino fundamental a partir de um questionário contendo perguntas abertas. Alguns gestores de ensino e também algumas respostas dos questionários dos professores apresentaram o termo 'lectoescrita', que se refere ao ensino e aprendizagem da leitura e da escrita, e suas relações.

As pesquisadoras Emília Ferreiro \& Ana Teberosky desenvolveram os estudos baseados na psicogênese da língua escrita, que tem como premissa que a aprendizagem da leitura e da escrita é um processo evolutivo. A criança formula por si mesma algumas normas ou regras sobre o sistema da escrita, ao mesmo tempo em que constrói um código de sinais. Quanto maior existir a interação com os modelos convencionais de escrita (sintético, analítico e global) maior será a influência destes modelos em seu processo de construção do conhecimento (BIZZOTTO et al. 2010: 2224). Este foi um aspecto que se revelou proeminente para a investigação, desta forma concentrou-se nos estudos existentes sobre lectoescrita e como poderiam integrar-se aqueles da legibilidade e leiturabilidade, ou suas inter-relações, passando, desta forma a ser um dos focos principais da pesquisa.

Outro fator determinante em relação à aprendizagem da leitura infantil é a rede de intermediações entre os repertórios da leitura e da escrita. Inicialmente, estas relações são independentes, mas se integram no decorrer da aprendizagem, logo, em alguns casos, o ensino de algumas relações resulta em transferências para novas relações (ROSE, 2005). Este processo é o que se nomeia de aprendizagem da lectoescrita.

O Método Lêcom, tem como base um dos fundamentos da lectoescrita, que é o professor como mediador/modelo para o aluno iniciante na leitura e na escrita. Para isso, no método criado, foi realizada uma tentativa de reproduzir o procedimento de escrita na lousa do professor de forma mais aproximada possível. Para o desenvolvimento do Método e sua aplicação um conjunto de etapas e ferramentas metodológicas foi utilizado, entre eles o uso de critérios ergonômicos baseados na legibilidade, leiturabilidade e leitura à distância (explicado no tópico 2.3), foco deste artigo. 


\section{CONTEÚDO}

\subsection{Legibilidade e Leiturabilidade}

Apesar de termos conhecidos, mas que muitas vezes se confundem no âmbito da prática do design e da tipografia, os mesmos apresentam diferenças significativas, tornando-se necessário relembrar de maneira sucinta do que se trata cada um.

Legibilidade está relacionada à facilidade do reconhecimento inteiro e individual de caracteres, assim como, a visibilidade e o reconhecimento das palavras, considerando níveis de iluminação e distância de leitura. Além disso, um texto deve apresentar uma orientação espacial com características tipográficas que promovam uma melhor compreensão no contexto em que as palavras estão inseridas. Em relação ao leitor, deve ser evidenciado sua origem cultural e social, sua habilidade no reconhecimento dos caracteres e seu conhecimento prévio e linguístico (repertório léxico). Para um leitor iniciante, que caracteriza a leitura como reconhecimento letra a letra (operações de análise e síntese), os espaçamentos são determinantes, assim como o tamanho dos caracteres e a forma das palavras (TINKER, 1963; LUND, 1999; SASSOON \& WILLIANS, 2000; SOUZA, 2002; KATO, 2007; HEALY \& CUNNINGHAM, 2007; BEIER, 2009; KAMIKASE, 2010; GONÇALVES, 2010).

Já a leiturabilidade de um texto é um pouco mais complexa que a legibilidade, envolve o processo de compreensibilidade de um determinado texto, sendo que alguns aspectos da legibilidade são também considerados, tais como, condições adequadas de um texto para viabilizar a leitura (legibilidade de impressão e apresentação visual). Além disso, existem os fatores pertinentes ao leitor, entre eles: a sua própria compreensão; seus interesses e motivações; seu repertório léxico; e o nível de letramento que o indivíduo se encontra (MCLAUGHIN, 1968; HARRISON, 1980; ALDRICH \& FENNELL, 1991; SOUSA, 2002; VALÉRIO, 2007; RUMJANEK, 2009; KAMIKASE et al, 2011; FONTOURA \& FUKUSHIMA, 2012).

Não se pode dissociar o aprendizado da leitura e da escrita. Em muitos trabalhos envolvendo estudos de legibilidade e leiturabilidade, a escrita não emerge como um elemento relevante para a obtenção de conhecimentos sobre o reconhecimento e entendimento dos textos. Ao aprofundarmos nas pesquisas realizadas por pedagogos e estudiosos na área da educação, observamos que há diversas possibilidades de se fazer a correlação entre o aprendizado da leitura e da escrita. Desta forma, para o desenvolvimento do Método Lêcom, foi essencial a união entre estes dois aspectos, portanto, foi primordial se apropriar de alguns fundamentos da lectoescrita para sua própria construção.

\subsection{Lectoescrita}

Apesar da leitura e a escrita estarem inteiramente relacionadas, ela é na verdade a antítese da escrita, visto que, cada uma atua em pontos distintos do cérebro. A escrita é uma habilidade, já a leitura é uma aptidão natural. A escrita originou-se de uma elaboração, enquanto a leitura desenvolveu-se com a compreensão da humanidade e dos recursos da palavra escrita (FISHER, 2006). 
A leitura e a escrita constituem-se o centro das práticas educativas na cultura escolar, transformando-se em verdadeiros instrumentos para a promoção do aluno ou para legitimar o seu fracasso (BAZERMAN, 2007).

Rose (2005) define os repertórios de leitura e escrita como uma rede de relações. A princípio, essas relações são independentes, mas podem se integrar à medida que algumas delas são aprendidas. A partir desta integração, novas relações podem se estabelecer, como por exemplo, o ensino de algumas relações resulta em transferência para novas relações, com pouco ou nenhum ensino explícito destas novas relações.

Sabemos por Bizzotto et al. (2010:22-24) que a aprendizagem da leitura e da escrita é um processo evolutivo. A criança formula algumas normas ou regras sobre o sistema de escrita, ao mesmo tempo em que constrói um código próprio de sinais. Ao imitar e ao recriar os modelos de textos com as quais vai interagindo, a criança incorpora novas experiências e descobertas a seus conceitos iniciais. Ler e escrever envolve um processo contínuo de construção e reconstrução, com normas próprias do código linguístico. Até que se consiga estabelecer uma completa relação entre a fala e a escrita, o aluno precisa de uma grande e diversificada interação com a leitura e a escrita, enquanto vai construindo seu próprio conhecimento sobre o que é ler e escrever, baseando-se nos modelos que o meio social lhe oferece.

Na construção do Método Lêcom, além de unir aspectos relacionados ao aprendizado da leitura e escrita, e suas relações, foi priorizado como as crianças imitam e recriam modelos, seja a partir de textos existentes ou até mesmo dos professores como modelo de escrita.

No tópico a seguir, apresentamos uma descrição das etapas do método desenvolvido, enfatizando os aspectos que envolvem os procedimentos ergonômicos inerentes ao Lêcom.

\subsection{As etapas do Método Lêcom}

O método proposto foi desenvolvido para crianças do segundo ano do ensino fundamental de escolas públicas brasileiras e apresenta várias etapas para avaliação do rendimento de leitura com crianças em início de aprendizagem. Além disso, com o Método Lêcom espera-se observar as diferenças em relação ao rendimento de leitura entre os três estilos de letras mais usuais com as quais as crianças aprendem e se familiarizam no contexto do ensino fundamental: a caixa alta, a cursiva e a caixa baixa, assim como suas preferências em relação aos três estilos. $O$ foco deste artigo encontra-se nas etapas 1, 5 e 6 (Tabela 01), que apresentam aspectos relacionados à ergonomia.

Tabela 1: Etapas e aplicabilidade do Método Lêcom.

\begin{tabular}{l|l}
\hline Etapas & Aplicabilidade \\
\hline Primeira & $\begin{array}{l}\text { Construir três frases seguindo os princípios tipográficos para crianças nos } \\
\text { três estilos, caixa alta, caixa baixa e cursiva. Esta etapa deve ser realizada } \\
\text { com o auxílio de um pedagogo. }\end{array}$ \\
\hline
\end{tabular}




\begin{tabular}{l|l}
\hline Segunda & $\begin{array}{l}\text { Preparar a sala de aula previamente com o Datashow, tabela de Snellen }{ }^{1}, \\
\text { mesa, cadeira e câmera posicionados. }\end{array}$ \\
\hline Terceira & $\begin{array}{l}\text { Realizar a escolha do participante de forma randômica e chamar para a sala } \\
\text { previamente organizada. }\end{array}$ \\
\hline Quarta & $\begin{array}{l}\text { Convidar o participante para realizar o teste com a tabela de Snellen. Se a } \\
\text { AV (acuidade visual) estiver nos parâmetros recomendados, dar continuidade } \\
\text { ao experimento. }\end{array}$ \\
\hline Quinta & $\begin{array}{l}\text { O participante deve se sentar em outra mesa com uma cadeira. } \\
\text { Nesta mesa deve constar um lápis e uma borracha. Projetar a primeira frase } \\
\text { (caixa alta, caixa baixa ou cursiva). }\end{array}$ \\
\hline Sexta & Pedir para o participante realizar a leitura em voz alta. \\
\hline Sétima & Pedir para o participante copiar com sua letra a frase. \\
\hline Oitava & $\begin{array}{l}\text { Pedir para o participante transcrever para o papel o que compreendeu da } \\
\text { frase. }\end{array}$ \\
\hline Nona & $\begin{array}{l}\text { Repetir os passos 5, 6 e 7 mais duas vezes com os outros estilos de } \\
\text { tipografia. }\end{array}$ \\
\hline Décima & $\begin{array}{l}\text { Realizar o teste de preferência sobre o melhor estilo de letra para realizar a } \\
\text { leitura. }\end{array}$ \\
\hline
\end{tabular}

Fonte: Lourenço, 2016.

A etapa 1 da construção do método consiste em filmar a professora do segundo ano escrevendo as frases em caixa alta, caixa baixa e cursiva. A ideia principal da filmagem é poder observar a maneira como o educador está escrevendo, assim como o movimento, direção da escrita e o tempo em que se realiza o processo. Deste modo, pode-se verificar, em situação real, como o ato da escrita é realizado em sala de aula e transmitido para o aluno que irá realizar a leitura no teste (Figura 01). Outro fator relevante é a forma como o aluno observa a formação da frase. Um dos fundamentos da lectoescrita aponta que um fator positivo é a possibilidade da criança observar o ato da formação das letras e palavras antes de realizar uma leitura. Deste modo, o professor se torna um modelo de referência (FERREIRO \& TEBEROSKY: 2007).

Figura 01: Professora escrevendo em letra cursiva a frase para o experimento.

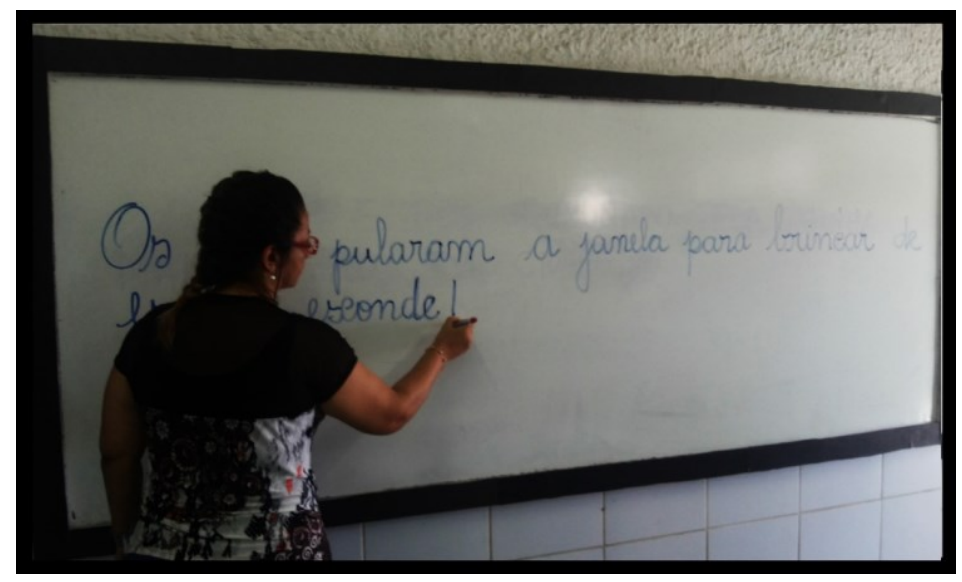

Fonte: Lourenço, 2016.

Para escrever as três frases, em caixa alta, a professora levou em média 57 segundos, para as frases no estilo cursivo uma média de 46 segundos e em caixa baixa, média de 46 segundos. A professora que auxiliou no experimento piloto

\footnotetext{
${ }^{1}$ Para o teste de Snellen, houve a participação de oftalmologista, orientando o pesquisador na
} sua aplicação. 
(professora Gédia Cristina) apresentou informações importantes de sua vivência e experiência com crianças em sala de aula. Essas informações nortearam a elaboração do método.

Uma delas foi:

O professor é o modelo para o aluno e não apenas um reprodutor da escrita. As pesquisas que envolvem leitura muitas vezes não consideram o professor como escriba, e é de fundamental importância para a criança e seu aprendizado essa inserção.

Essa afirmação reforçou o interesse desta investigação, qual seja a união de fundamentos da lectoescrita, juntamente com aspectos da legibilidade e leiturabilidade para observar, se combinados, podem gerar um modelo para um método avaliativo de leitura.

Após a coleta da filmagem, foi gerada uma animação. Essa animação consiste em uma reprodução mais próxima possível do ato de escrita do professor. Na aplicação do método as frases são projetadas por datashow no tempo médio em que a professora utilizou para escrever cada frase.

Como seria impossível em um experimento controlado ter a professora presente escrevendo cada frase no quadro, a projeção da animação das frases, com o tempo que a professora escreveu no quadro, foi o meio escolhido que mais se assemelha com a ação real.

A concepção é que a criança no momento do experimento se sinta o mais próximo da sua realidade em sala de aula, para que não ocorra nenhum tipo de interferência por indução da pesquisa/pesquisador, já que este também não poderia escrever as frases. A animação demonstra o movimento e o tempo da escrita de uma frase em caixa alta, outra com letra cursiva e uma última com tipografia caixa baixa, que estão presentes nos livros didáticos do ensino fundamental 2. É importante destacar que a frase em caixa baixa aparece animada como se estivesse datilografada, para dar a ideia de livro impresso.

Outro aspecto a se considerar, são os fatores ambientais e níveis de iluminação do ambiente, características importantes quando se trata de testes de legibilidade. A aplicação do método foi realizada em sala de aula normal, cedida pela escola e que as crianças costumam usar quase todos os dias no ano letivo. Portanto, as crianças estarão em um ambiente conhecido e em condições normais e adequadas para elas.

A criança foi chamada para a sala de aula sozinha, sendo que, preliminarmente, a sala de aula foi organizada pelo pesquisador para a realização do experimento. Uma cadeira e uma mesa foram alocadas a uma distância de quatro metros do quadro em que as frases foram projetadas. Essa distância foi determinada pelo tamanho da própria sala. Mesmo tendo realizados seus estudos em ergonomia voltados especificamente para adultos, alguns princípios propostos por lida (2005) foram utilizados. Conforme o autor recomenda-se que a altura das letras e números seja $1 / 200$ da distância, em milímetros, por exemplo, se a distância de leitura for de 1 metro, a altura da letra deveria ser de $0,5 \mathrm{~cm}$. 
Optou-se por dispor a cadeira e a mesa no meio da sala (4 metros de distância), pois seria uma média em relação a todos os alunos sentados no dia a dia escolar (Figura 02).

Figura 02: Exemplo de como o aluno foi disposto no experimento.

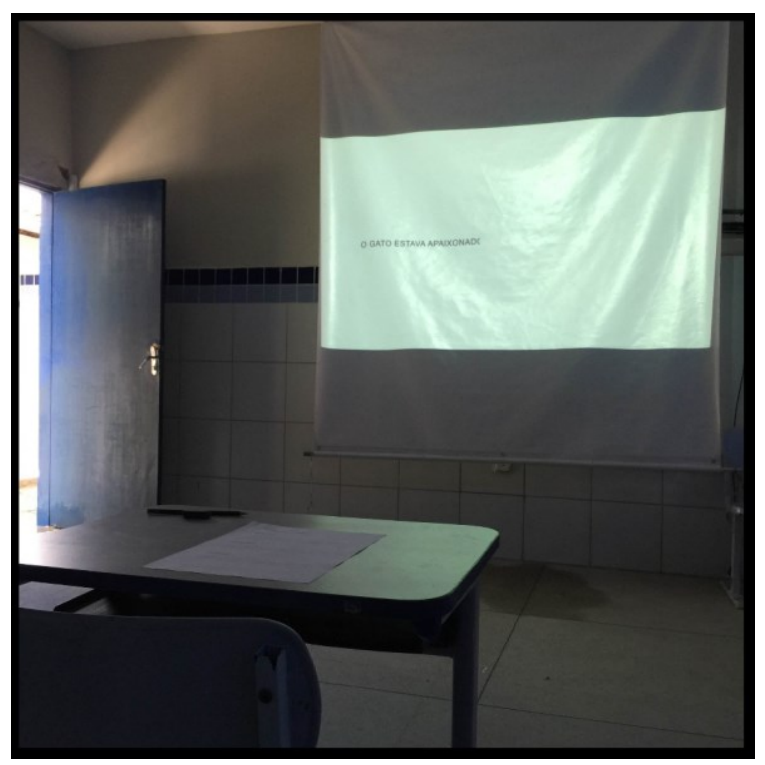

Fonte: Lourenço, 2016.

Em relação às medidas, tem-se também a distância da projeção em relação ao chão, no caso $75 \mathrm{~cm}$. Para que as letras ficassem sempre no mesmo tamanho, a projeção foi realizada em uma medida de $190 \times 110 \mathrm{~cm}$. Além disso, foi considerado que, com essa altura, o campo de visão máxima ${ }^{2}$ do leitor iniciante estaria em ângulos adequados (Figura 03).

Figura 03: Cones de visão ótima, segundo Itiro lida.

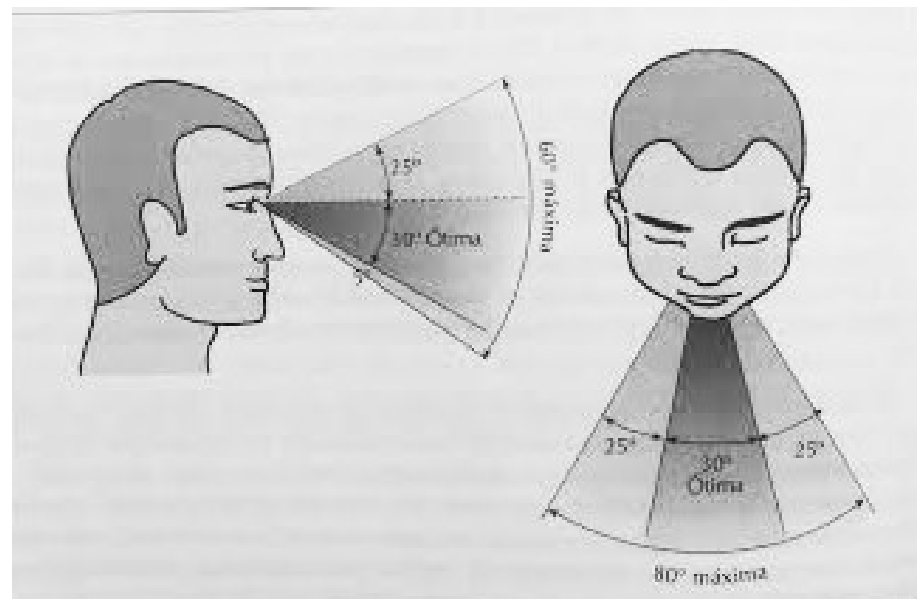

Fonte: lida (2005:290).

\footnotetext{
2 Visão Máxima é a visão que se consegue, movimentando-se somente os olhos, sem movimentar a cabeça. Situa-se até $25^{\circ}$ acima da linha horizontal de visão e $35^{\circ}$ abaixo da mesma e, lateralmente, faz uma abertura horizontal de $80^{\circ}$ (IIDA, 2005: 290).
} 
A seguir uma imagem com os detalhes das medidas (Figura 04). É importante salientar que a lona de projeção e o datashow foram os mesmos utilizados para todas as crianças.

Figura 04: Arrumação do ambiente para o experimento.

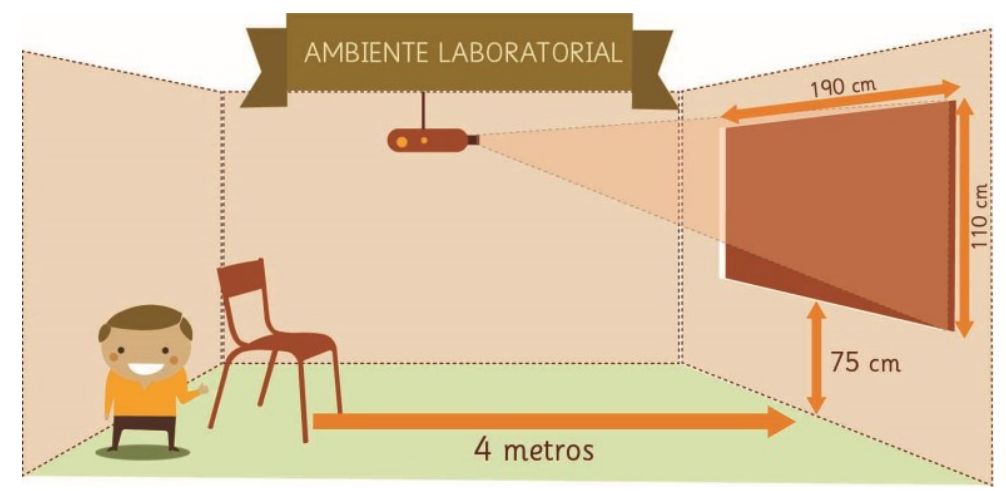

Fonte: Lourenço, 2016.

A criança foi convidada a se sentar e a observar a primeira das três frases. Antes de detalhar mais sobre o experimento, é necessário destacar as medidas que foram utilizadas no quadro para as tipografias. Optou-se por utilizar as medidas em centímetros, pois trata-se de uma projeção. Seguindo os postilados de lida (2005), na medida de 4 metros, o corpo da tipografia deveria ter 2 centímetros. Todavia o autor não deixa claro essas medidas para as crianças e nem destaca sobre o uso da tipografia cursiva. Optou-se por aumentar a altura de $x$, pois trata-se de crianças, e um tamanho de tipografia maior é considerado mais adequado para a legibilidade dos textos (TINKER, 1963; ZACHRISSON, 1965).

Quanto às proporções, lida (2005) recomenda que: a altura das letras minúsculas (neste caso, 3,5 centímetros) corresponda a $2 / 3$ da altura das maiúsculas (5 centímetros). Não foi encontrada uma medida específica sobre as proporções específicas da tipografia cursiva em detrimento dos outros estilos. Já Gibson (2009) não é tão preciso, mas menciona que não deve haver distorções na proporção das letras, assim como os intervalos entre elas não podem ser nem muito pequenos, nem muito grandes, para que a leitura seja confortável.

A altura da caixa alta da tipografia Arial possui medida de $5 \mathrm{~cm}$. A tipografia cursiva, Mamãe que nos faz, possui altura de $x$ de $2,5 \mathrm{~cm}$ e ascendentes e descendentes de $2,5 \mathrm{~cm}$. Já a tipografia, Times, caixa baixa possui altura de $x$ de $3,5 \mathrm{~cm}$ e suas ascendentes com $1,0 \mathrm{~cm}$ e descendentes com $1,5 \mathrm{~cm}$ (Figura 05). Foi considerado importante que as três frases nos três estilos de letras, quanto projetadas, tivessem um tamanho de linha muito próximo. 
Figura 05: Tipografias e medidas utilizadas no experimento. altura de caixa alta- $5 \mathrm{~cm} \mid \mathrm{O}$ GATO ESTAVA

Fonte: Arial

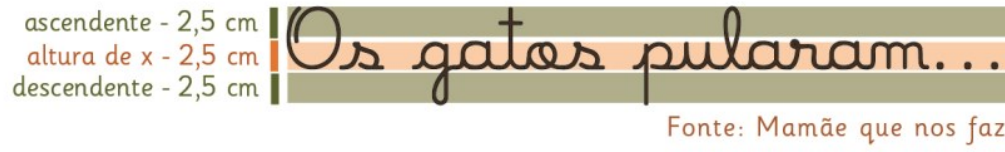

ascendente $-1,0 \mathrm{~cm}$ altura de $x-3,5 \mathrm{~cm}$
descendente $-1,5 \mathrm{~cm}$ gata queria Multo...

Fonte: Lourenço, 2016.

Os espacejamentos também foram alterados, a tipografia cursiva apresentava um entreletras muito justo e foi necessário aumentá-lo. Nos três estilos o espaço entrepalavras foi aumentado também.

Após ver a formação da primeira frase, a criança foi convidada a ler em voz alta a frase que acabou de ser formada. De acordo com os preceitos da lectoescrita, para as crianças a leitura não pode ser concebida sem voz, a leitura é interpretada como "olhar", enquanto se exige "falar" ou "dizer" para julgar um ato como leitura (FERREIRO \& TEBEROSKY, 2007). Pode-se acrescentar que:

$\mathrm{Na}$ concepção tradicional da leitura, o significado aparece em algum momento, magicamente, atraído pela oralização. É graças à emissão sonora que o significado surge, transformando assim a série de fonemas numa palavra. Segundo a visão de vários autores contemporâneos, o circuito signo visual-tradução-sonora-significação não é um circuito inevitável, mas sim que nos surge como tal em virtude da importância desmesurada que a leitura em voz alta adquire na prática escolar. (FERREIRO \& TEBEROSKY, 2007: 286)

Logo após a leitura foi entregue para a criança uma folha para que ela copie do quadro o que acabou de ler. A criança não precisa escrever com a mesma letra e ela foi informada sobre isso. O mesmo procedimento ocorreu com as outras duas frases. $\mathrm{O}$ motivo para ela escrever a frase é para poder observar se a criança é somente um copista, ou se ela realmente já consegue ler com certa fluência e reconhecer os caracteres nos três estilos. Outro princípio da lectoescrita é a cópia, a criança pode muitas vezes copiar muito bem, mas não ser um leitor fluente, ou seja, ela estará apenas desenhando o caractere.

As crianças já estão habituadas com a letra da professora, com o movimento da letra e até com a postura da educadora perante a sala. Portanto, mesmo sem o professor presente, a criança poderá acompanhar a construção da frase. Ferreiro \& Teberosky, em um dos seus testes envolvendo leitura apontam o seguinte:

Assinalamos que optamos por escrever a oração diante da criança, em lugar de apresenta-la já escrita, para fazê-la assistir ao ato da escrita, e fixar, dessa maneira, a ordem "esquerda-direita", porque nada assegura que a criança aceite esta orientação convencional. (FERREIRO \& TEBEROSKY, 2007: 118) 
As frases foram projetadas uma de cada vez. A frase em caixa alta com 57 segundos, a frase com letra cursiva com 46 segundos e em caixa baixa com 46 segundos. Uma única frase apareceu por vez na projeção e em uma única linha. As três frases foram animadas nos três estilos de fonte. Sendo assim, cada criança leu três frases, uma em cada estilo. A distribuição das frases foi apresentada de modo aleatório entre cada participante. É importante destacar que a criança realizou a leitura de uma frase de cada vez e posteriormente, realizou a cópia da frase.

Logo após, foi entregue uma folha para a criança escrever o que compreendeu de cada frase lida e copiada. Nation \& Snowling (1997) que, ao compararem vários testes de compreensão leitora, concluíram que avaliações individuais com questões abertas (neste caso, escrever o que compreendeu das frases) são as mais adequadas quando para leitores iniciantes, apontando, igualmente, para a importância de se considerarem as características individuais desses leitores.

Para finalizar a criança recebeu uma nova folha com uma pergunta e assinalar a resposta (Figura 06).

Figura 06: Pergunta após o teste de leitura e escrita.

\section{1) Qual o tipo de letra você acha mais fácil de ler: \\ a) A LETRA BASTÃO \\ b) G letra de mãa \\ c) A letra que vem nos livros}

Fonte: Lourenço, 2016.

Os critérios utilizados para análise foram: (1) esforço, (2) erros e (3) opinião dos leitores. Esforço está relacionado ao tempo de leitura por frase, ou seja, quanto tempo cada criança levou para ler cada frase, aspecto esse relacionado à legibilidade. Erros correspondem à contagem e análise dos erros como critérios de avaliação e reconhecimento dos caracteres e palavras, outro método de legibilidade $\mathrm{e}$ leiturabilidade, visto que se avalia também o conteúdo. Por fim, opinião dos leitores, de forma a compreender sua preferência por determinado estilo, refere-se, portanto ao desenho do caractere utilizado (legibilidade).

Para não haver uma pré-disposição onde as crianças pudessem lembrar-se do conteúdo da última frase, a segunda pergunta foi aplicada três vezes, quando a criança leu a primeira frase ela foi interrogada sobre o conteúdo desta e assim sucessivamente. Os testes foram gravados por meio de áudio para obter o tempo de leitura e observar quando e onde foram cometidos os erros de leitura, para posteriormente realizar a análise qualitativa. 


\section{CONSIDERAÇÕES FINAIS}

Como exposto anteriormente, testes de legibilidade e leiturabilidade com crianças no Brasil são escassos. Portanto, a criação de um método adequado à realidade brasileira para mensurar como as crianças estão realizando a leitura nas escolas públicas se apresenta como um instrumento para suprir uma real necessidade, tanto do ponto de vista dos estudos de legibilidade/leiturabilidade em Design e Ergonomia no país, quanto pela contribuição para o campo educacional.

No Método Lêcom foram unidos princípios da leitura e da escrita, sendo importante o reconhecimento do papel preponderante da lectoescrita. Para isso, na construção do método foi necessário entender e utilizar fundamentos da ergonomia como pressupostos, especificamente relacionados à legibilidade e a leiturabilidade para o leitor iniciante, e em outra dimensão, os próprios argumentos da ergonomia visual para a construção dos procedimentos experimentais (como distância de leitura, ângulo de visão, posição do leitor, dimensionamento da informação verbal, entre outros) expostos no artigo. Portanto, a ergonomia favorece o método em sua acepção e em sua formatação. Desta forma, em sua aplicação, os pressupostos ergonômicos são fundamentais para que tanto o método possa funcionar, quanto seja aplicado em concordância com os princípios dos fatores humanos envolvidos.

No campo do Design e Ergonomia, buscou-se contribuir para o preenchimento de uma lacuna, elaborando um método para avaliação do rendimento de leitura com crianças brasileiras envolvendo legibilidade, leiturabilidade e fundamentos da lectoescrita focado na realidade do país. Assim buscaram-se também adequar às condições padrão majoritária de ensino, ou seja, as escolas públicas; com a participação dos agentes educacionais; conduzido pelo pesquisador com a supervisão dos docentes; no próprio contexto escolar (ambiência); fortalecendo assim, uma condição experimental mais próxima do processo de ensino/aprendizagem de crianças em fase de letramento. Esta perspectiva, onde se busca uma condição experimental laboratorial contextualizada, não é comum, todavia, foi aplicada com sucesso em escolas públicas do Estado da Paraíba, em especial na cidade de Cabedelo.

Não obstante, o método será adotado em outras ambiências, a fim de confirmar o seu sucesso, e encontra-se, do ponto de vista teórico, em busca da construção de um modelo avaliativo do rendimento de leitura (Modelo Lêcom), por crianças em qualquer nível de letramento, ou mesmo para jovens leitores fluentes.

Com a aplicação de tal método/modelo, poderemos contribuir também no campo educacional, em duas dimensões: (a) na compreensão da indissociabilidade do processo de ensino da leitura e escrita; (b) na compreensão por parte dos agentes educacionais das questões relativas ao uso de tipografia, e seus aspectos estéticos, semânticos e ergonômicos dos dispositivos, quer nos livros, nas fichas de aula, nos murais ou na lousa.

\section{REFERÊNCIAS BIBLIOGRÁFICAS}

ALDRICH-RUENZEL, N.; FENNELL, J. (Eds). Designer's Guide to Typography. Nova lorque: Watson Guptill Publicationsed, 1991. 
BAZERMAN, C. Escrita, Gênero e Interação Social. São Paulo: Cortez Editora, 2007.

BEIER, S. Typeface Legibility: towards defining familiarity. 268 f. (Tese de Doutorado não publicada), Royal College of Art. Londres, 2009. Disponível em:

<http://researchonlinerca.ac.uk/957/1/Sofie_Beier_Typeface_Legibility_2009.pdf > Acesso em: 15 de agosto de 2012.

BIZZOTTO, I. M.; AROEIRA L. M.; PORTO A. Alfabetização Linguística: da teoria à prática. $1^{\text {a }}$ Edição. Editora Dimensão: Belo Horizonte, 2010.

FERREIRO, E.; TEBEROSKY, A. Psicogênese da Língua Escrita. $4^{\mathrm{a}}$ ed. Porto Alegre: Artes Médicas, 2007.

FISHER, S. R. História da Leitura. Tradução: Cláudia Freire. São Paulo: Editora UNESP, 2006.

FONTOURA, A. M.; FUKUSHIMA, N. Vade-mécum de Tipografia. Editora Insight, 2012.

GIBSON, D. The Wayfinding Handbook: Information Design for Public Places. Nova lorque: Princeton, 2009.

GONÇALVES, C. H. C. Estudo da metodologia de projeto gráfico aplicado ao contexto de uma empresa jornalística, (Dissertação de Mestrado em Design, não publicada). Faculdade de Arquitetura, Artes e Comunicação, Universidade Estadual Paulista, Bauru, 2010.

HARRISON, C. Readability in the classroom. Nova lorque: Cambridge University Press, 1980.

HEALY, A. F.; CUNNINGHAM, T. F. A developmental evaluation of the role of word shape in word recognition. Memory and Cognition v.20, n.2, p. 141-150, 1992.

IIDA, I. Ergonomia: projeto e produção. São Paulo: Edgard Blücher, 2005.

KAMIKASE, M. S.; NASCIMENTO R. A.; SANTOS J. E. Bulas e Cartelas de Medicamentos: Possíveis soluções de leiturabilidade através do Design Gráfico. Revista ARCOS DESIGN, v. 6, n. 1 p.42-59, Rio de Janeiro, 2011.

KATO, M. O aprendizado da leitura. São Paulo: Martins Fontes, 1985.

LOURENÇO, D. A. Desenvolvimento de um método para avaliação do rendimento de leitura com crianças brasileiras envolvendo legibilidade, leiturabilidade e fundamentos da lectoescrita - Método Lêcom. (Tese de Doutorado não publicada), Departamento de Design, Universidade Federal de Pernambuco, UFPE, Recife, 2016.

LUND, O. Knowledge construction in Typography: the case of legibility research in the legibility of sans serif typefaces, (Tese de Doutorado não publicada), Department of Typography \& Graphic Communication, The University of Reading, Reino Unido, 1999.

MCLAUGHLIN, G. H. Proposals for British readability measures. Third international reading symposium. p. 186-205, 1968.

NATION, K.; SNOWLING, M. Assessing reading difficulties: the validity and utility of current measures of reading skill. British Journal of Educational Psychology, v. 67, n.3, p. 359-370, 1997.

ROSE, J. Análise Comportamental da aprendizagem da leitura e escrita. Revista Brasileira de Análise do Comportamento. Brazilian Journal of Behavior Analysis, v.1, n.1, p. 2950, 2005. 
RUMJANEK, L. Construção de textos para estudo de legibilidade com crianças em processo de alfabetização. $9^{\circ}$ USIHC: Curitiba, 2009.

SASSOON, R.; WILLIAMS, A. Why sasson? Material complementar que acompanha a tipografia Sassoon. Londres, 2000.

SOUSA, M. Guia de Tipos: Métodos para o uso de fontes em PC. 2002. Disponível em:< www.guiadetipos.pt.vu> Acesso em: 22 de agosto de 2012.

TINKER, M. A. Legibility of print. lowa State University Press, Ames, 1963.

VALÉRIO, M. Â. F. M. Uma Prevenção para Todos? Análise do Grau de Leiturabilidade, Peso da Régua, 2007.

ZACHRISSON, B. Studies in the legibility of printed text. Uppsala: Almqvist \& Wicksell, 1965. 